\title{
COMPORTAMENTO DO MARACUJAZEIRO AMARELO, VARIEDADE AFRUVEC, ANTE UMA POPULAÇÃO DE FUSARIUM SOLANI, AGENTE CAUSAL DA PODRIDÃO DO COLO
}

\author{
C.J. Bueno ${ }^{1}$, I.H. Fischer ${ }^{2}$, M.C.M. Parisi ${ }^{1}$, E.L. Furtado ${ }^{3}$ \\ ${ }^{1}$ Instituto Biológico, Centro Experimental Central, Rod. Heitor Penteado, km 3, CEP 13012-970, Campinas, \\ SP, Brasil. E-mail: cjbueno@biologico.sp.gov.br
}

\section{RESUMO}

O objetivo do presente trabalho foi verificar o comportamento do maracujazeiro amarelo, variedade Afruvec, ante uma população de Fusarium solani, obtida desse mesmo hospedeiro. $\mathrm{O}$ delineamento adotado foi o de blocos ao acaso, contendo dez tratamentos (nove isolados e tratamento testemunha), com quatro repetições, sendo cada parcela representada por um vaso contendo uma planta. Um disco do meio de cultura, colonizado com cada isolado do fungo, foi inoculado no colo ferido das plantas da variedade Afruvec, dois meses após a semeadura. Avaliou-se a patogenicidade, a incidência (número de plantas mortas) e a severidade da doença (comprimento da lesão no colo), até os sessenta dias após a inoculação. A variedade Afruvec foi suscetível ao fungo e apresentou variabilidade quanto à incidência e severidade da doença diante dos diferentes isolados. A população do fungo apresentou variabilidade em relação à agressividade. Com a evidência de diversidade genética na população do fungo, recomenda-se, também, nos testes de seleção de materiais ao patógeno, a avaliação desses materiais em diferentes localidades com histórico da doença ou inoculação com uma mistura de isolados do fungo, a fim de se conhecer a resistência ampla do genótipo ao patógeno.

PALAVRAS-CHAVE: Maracujá, melhoramento genético, resistência genética, Fusarium solani, variabilidade genética.

\begin{abstract}
BEHAVIOUR OF YELLOW PASSION FRUIT, AFRUVEC VARIETY, IN RELATION TO A POPULATION OF FUSARIUM SOLANI, CAUSAL AGENT OF COLLAR ROT. The objective of the present work was to verify the behavior of yellow passion fruit, Afruvec variety, in relation to a population of Fusarium solani, obtained from this crop. The experimental delineation was random blocks, containing 10 treatments [9 isolates and 1 control treatment], with 4 repetitions, each plot being represented by a vase containing a plant. A disk of culture medium colonized by each isolate of the fungus was inoculated in the wounded collar region of the plants of the Afruvec variety two months after sowing. The appraised parameters were: the pathogenicity, the incidence (number of dead plants) and the severity of the disease (length of the lesion in the collar region), until 60 days after inoculation. The Afruvec variety was susceptible to the fungus and also presented variability as to the severity of the disease and incidence in relation to the different isolates. The population of the fungus showed variability in regard to aggressiveness. In light of the evidence of genetic diversity in the F. solani population, it is also suggested, in the tests of selection of materials to the pathogen, that these materials should be evaluated in different places with a history of the disease or inoculation with a pool of isolates of the fungus, in order to know the wide resistance of the genotype to the pathogen.
\end{abstract}

KEY WORDS: Passion fruit, genetic breeding, genetic resistance, Fusarium solani, genetic variability.

O Brasil destaca-se como o maior produtor mundial de maracujá-amarelo (Passiflora edulis $\mathrm{f}$. flavicarpa), com uma produção aproximada de 491.619 toneladas (FNP CONSUltoria \& Agroinformativos, 2007). A cultura está sujeita à ocorrência de várias doenças e, dentre elas, destaca-se a podridão do colo, causada por Fusarium solani, que provoca significativo decréscimo na produtividadee constantes migrações da cultura para regiões livres do patógeno. Os sintomas da doença consistem em uma leve

${ }^{2}$ Pólo Regional do Centro Oeste, Unidade de Pesquisa e Desenvolvimento de Bauru, Bauru, SP, Brasil.

${ }^{3}$ Universidade Estadual Paulista, Faculdade de Ciências Agronômicas, Botucatu, SP, Brasil. 
murcha dos ponteiros, acompanhada de alteração na coloração da folha para um verde-pálido, ocorrendo, posteriormente, murcha drástica, desfolha e morte das plantas, em virtude do completo anelamento necrótico do colo da planta. São também descritos intumescimento e rachaduras da casca, na região do colo afetado, exibindo uma coloração arroxeada nas bordas das lesões e formando, sob condições de elevada umidade, estruturas pouco maiores que grãos de areia, de coloração avermelhada, que nada mais são do que os peritécios do patógeno, ou seja, a fase perfeita do fungo (FISCHER et al., 2005a).

Omanejo das doenças causadas por fitopatógenos de solo é realizado, preferencialmente, pelo uso de cultivares resistentes, o que, de acordo com CAMARGO; BERGAMIN FilHo (1995), é o método preferido pelos agricultores, por ser mais barato e de fácil utilização.

Com relação ao comportamento de maracujazeiros à podridão do colo, existem trabalhos que relatam elevada variabilidade de genótipos de $P$. edulis (maracujá-roxo), de P. edulis f. flavicarpa e outros que descrevem materiais resistentes a F. solani (RONCATTO et al., 2004; Fischer et al., 2005b). Além da detecção de diferentes materiais com resistência a F. solani e com potencial para utilizaçãocomercial como porta-enxerto demaracujazeiroamarelo(RONCATTOetal., 2004; FISCHER et al., 2005b), LIN; CHANG (1985) relataram que algumas linhagens de P. edulis f. flavicarpa apresentam-se mais resistentes ao patógeno, quandocomparadasa P.edulis f. edulis, devendo ser mais exploradas em programas de melhoramento.

Em condições de casa-de-vegetação, principalmente, poucos trabalhos testam materiais de maracujazeiro amarelo diante de uma mistura de isolados do patógeno, para se saber o nível de resistência. Além disto, poucos trabalhos demonstram o porquê de se inocular uma mistura de isolados em testes de reação de resistência de materiais, ante patógenos.

Diante da importância docultivo do maracujazeiro amarelo no Brasil, da importância da doença causada pelofungo $F$. solanina cultura, dos poucos trabalhos de avaliação do comportamento da resistência de variedades do maracujazeiro amarelo ante uma população do patógeno e, também, da falta de conhecimento da agressividade de isolados do fungo, idealizou-se o presente projeto. Portanto, oobjetivo deste trabalhofoi verificar ocomportamento demaracujazeiro amarelo, variedade Afruvec, diante de uma população de $F$. solani, obtida da mesma cultura.

Utilizando-se de plantas de maracujazeiro amarelo, provenientes de diferentes localidades no Estado deSão Paulo e uma do Estado do Rio de Janeiro, com sintomas específicos de podridão do colo, procedeuse ao isolamento indireto do agente causal. Após a identificação das colônias do fungo $F$. solani, fez-se a purificação dos isolados e, em seguida, sua preservação pelo método de Castellani. A procedência de cada isolado está descrita na Tabela 1.

A variedade de maracujazeiro amarelo Afruvec, muito plantada no Estado deSão Paulo, foi utilizada nos testes de avaliação da patogenicidade do fungo, incidência e severidade da doença. As plantas foram desenvolvidas, diretamente, em vasos de dois litros, contendo uma mistura de solo, areia e esterco, na proporção de 2:1:1, previamente esterilizada. O delineamento experimental utilizado foi o de blocos ao acaso, contendo dez tratamentos (nove isolados descritos na Tabela 1 mais tratamento testemunha), com quatro repetições, sendo cada repetição representada por um vaso contendo uma planta. Os isolados utilizados nos testes foram cultivados em meio BDA, em estufa do tipo BOD, a $25^{\circ} \mathrm{C}$, por dez dias. A inoculação desses isolados foi realizada por meio da deposição de um disco de micélio, de 0,5 $\mathrm{cm}$ de diâmetro, de cada isolado, no colo ferido das plantas da variedade Afruvec, dois meses após a semeadura, de acordo com a metodologia de FISCHER etal. (2005b). Os parâmetros avaliados, semanalmente e até os sessenta dias após a inoculação dos isolados do fungo, foram: a) patogenicidade $=$ ausência $(-)$ ou presença $(+)$ de necrose no colo das plantas; $b$ ) incidência, contagem do número de plantas mortas e c) severidade da doença (podridão do colo), medindo-se o comprimento da lesão em $\mathrm{cm}$.

Após a finalização do experimento, procedeu-se ao reisolamento de todos os isolados do patógeno, nas plantas da variedade Afruvec, aleatoriamente, para cumprimento dos Postulados de Kock.

Tabela 1 - Procedência dos isolados de Fusarium solani, obtidos de maracujazeiro amarelo (P. edulis f. flavicarpa).

\begin{tabular}{ccc}
\hline Denominação & Procedência (localidade e propriedade) \\
\hline 7 & Pederneiras, SP & Fazenda Ribeirão Grande \\
8 & Bauru, SP & Sítio Santa Isabel \\
9 & Pederneiras, SP & Sítio Águas da Capivara \\
11 & Jaú, SP & Escola Agrícola Estadual Prof. “Urias Ferreira” \\
12 & Pederneiras, SP & Fazenda Ribeirão Grande \\
15 & Pederneiras, SP & Fazenda Ribeirão Grande \\
18 & Pederneiras, SP & Sítio Águas da Capivara \\
$\mathrm{E}$ & Borborema, SP & - \\
$\mathrm{RJ}$ & Campos dos Goytacazes, RJ & - \\
\hline
\end{tabular}


Com os dados de incidência (número de plantas mortas), calculou-se a área abaixo da curva de progresso da doença (AACPD), conforme metodologia de CAMPBELl; MAdDEN (1990). Posteriormente, os dados das áreas foram analisados por meio de análise não paramétrica e teste de comparação de múltiplas proporções, em nível de $5 \%$ de probabilidade (ZAR, 1999). Os dados de severidade da doença foram transformados em $\sqrt{ } x+0,5$ e as médias comparadas entre si por meio do teste de Tukey, em nível de 5\% de probabilidade.

Todos os isolados de F. solani de maracujazeiro amarelo inoculados foram patogênicos à variedade Afruvec (Tabela 2), sendo posteriormente reisolados. Analisando-seos parâmetrosseveridadeeincidência de plantas mortas conjuntamente(Tabela 2), constatou-se que o isolado 8 foi o menos agressivo, não provocando morte de plantas. $\mathrm{O}$ isolado 11, apesar de não diferir estatisticamente do 8, provocou a morte de plantas. O isolado 15 não diferiu estatisticamente dos isolados 8 e 11, quanto à severidade da doença, mas diferiu do isolado 8, quanto ao número de plantas mortas. Apesar do isolado 15 não ser tão agressivo em relação à severidade da doença, ao longo do tempo, causou severa morte de plantas. Assim como o isolado 15, os isolados9eRJ também resultaramem baixa severidade de doença, mas causaram grande número de plantas mortas. Os isolados 7, E e 12 não diferiram estatisticamente dos isolados 9 e RJ quanto à severidade da doença. No entanto, os isolados 7, Ee 12 apresentaram menor número de plantas mortas do que os isolados 9 e RJ. Dentre todos os isolados, o 18 foi o mais severo e, consequentemente, oquemaiscausoumortedeplantas.

A espécie P. edulis f. flavicarpa foi classificada como altamente suscetível a F. solani por Delanö̈ (1991), parcialmente resistente por SSEKYEWA et al. (1999), enquanto Lin; CHANG (1985) encontraram algumas linhagens resistentes ao patógeno, indicando a possibilidade do melhoramento genético intraespecífico ser mais promissor, considerando-se aspectos favoráveis de compatibilidade e produtivi- dade da espécie. Fischer et al. (2005b), além de terem detectado suscetibilidade da variedade Afruvec de maracujazeiro amarelo ante um isolado de F. solani, constataram grande variabilidade no que se refere à reação de resistência em outros materiais de maracujazeiro amarelo, diante do isolado do patógeno. De acordo com os dados apresentados na Tabela 2 do presente trabalho, além da constatação, também, da suscetibilidade da variedade Afruvec ao fungo F. solani, essa variedade apresentou variabilidade quanto à severidade da doença e número de plantas mortas em face da população do fungo levantada.

Após selecionar dois materiais resistentes e dois suscetíveis de maracujazeiro amarelo diante de um isolado de F. solani, Fischer et al. (2005b) avaliaram o comportamento desses materiais perante cinco diferentes isolados de F. solani do maracujazeiro. Neste ensaio, além dos autores constatarem grande variabilidade no que se refere à agressividade (número de plantas mortas e comprimento da lesão no colo das plantas) entre os isolados em um determinado material, verificaram, também, variabilidadequanto à resistência entre os materiais para cada isolado. Para se ter uma ideia da variabilidade, os materiais demaracujazeiro amareloclassificados, inicialmente, como suscetíveis e resistentes diante de um único isolado do patógeno, com a inoculação de outro isolado, passaram a se comportar todos como resistentes. No presente trabalho (Tabela 2), a variedade Afruvec de maracujazeiro amarelo também apresentou comportamento semelhante ao observado por FISCHER et al. (2005b), ou seja, há isolado que não provocou morte de plantas, mas causou pequena lesão no colo, enquanto outros causaram grande número de mortalidade de plantas e grandes lesões no colo; há, ainda, outros que propiciaram baixa lesão no colo e grande número de plantas mortas.

No presente trabalho (Tabela 2), assim como no de Fischer et al. (2005b), as populações do fungo $F$. solani levantadas apresentaram variabilidadequantoà agressividade, evidenciandosua diversidadegenética.

Tabela 2 - Patogenicidade, incidência e severidade da podridão do colo em maracujazeiro amarelo, variedade Afruvec, causadas por diferentes isolados de Fusarium solani obtidos de maracujazeiro amarelo.

\begin{tabular}{|c|c|c|c|}
\hline Isolados & Patogenicidade $^{1}$ & $\begin{array}{c}\text { Severidade da doença } \\
\text { (comprimento da lesão }-\mathrm{cm} \text { ) }\end{array}$ & $\begin{array}{c}\text { Incidência - AACPD de } \\
\text { plantas mortas }^{3}\end{array}$ \\
\hline Testemunha & $--^{*}$ & $0,0^{*} a^{2}$ & $0,0^{*} a^{3}$ \\
\hline 8 & + & $0,5 \mathrm{ab}$ & 0,0 \\
\hline 11 & + & $0,6 \mathrm{ab}$ & 17,5 \\
\hline 7 & + & 19 bc & 31,5 \\
\hline $\mathrm{E}$ & + & 1,2 bc & 42,0 \\
\hline 12 & + & 1,4 & 49,0 \\
\hline 15 & + & $0,8 \mathrm{ab}$ & 49,0 \\
\hline 9 & + & 1,3 bc & 66,5 \\
\hline RJ & + & 1,3 bc & 66,5 \\
\hline 18 & + & 2,9 c & 112,0 \\
\hline
\end{tabular}

*Média de quatro repetições; ${ }^{1}$ Ausência (-) ou presença (+) de necrose no colo das plantas; ${ }^{2}$ Médias transformadas em $\sqrt{\mathrm{x}+0,5}$ e quando seguidas por letras iguais, não diferem entre si (Tukey, $\mathrm{p}<0,05 ; \mathrm{CV}=21,7 \%$ ); ${ }^{3}$ Área abaixo da curva do progresso da doença (AACPD) - valores seguidos por letras iguais, não diferem entre si, em nível de 5\%, segundo teste não paramétrico de comparação de múltiplas proporções (ZAR, 1999). 
RonCATTO et al. (2004) estudaram o comportamento de Passifloráceas quanto à resistência ao fungo F. solani, em uma área da Faculdade de Ciências Agronômicas e Veterinárias da UNESP, Campus de Jaboticabal, SP, com histórico de ocorrência da doença. As espécies utilizadas por RonCATTO et al. (2004) foram P. edulis, P. edulis f. flavicarpa, $P$. nitida, $P$. cincinnata, $P$. giberti, $P$. laurifolia, $P$. morifolia, $P$. foetida e $P$. capsularis. Apenas as espécies $P$. giberti e $P$. nitida mostraram-se resistentes à doença, comportando-se como fontes promissoras de resistência em programas de melhoramento ou de enxertia. Além de $P$. giberti e $P$. nitida, as espécies P. mucronata (FIsCHER et al., 2005c) e P. caerulea (Cole et al., 1992) foram relatadas, também, como resistentes ao patógeno. Há relatos de espécies de Passifloraceas resistentes ao patógeno e com potencial para utilização comercial como porta-enxerto de maracujazeiro amarelo, mas esses materiais precisam ser verificados quanto à compatibilidade de enxertia, características agronômicas e reação de resistência ao patógeno.

Em consequência da constatação da variação de agressividade na população de $F$. solani utilizada no presente trabalho e no de FISCHER et al. (2005b), recomenda-se, nos testes de seleção de materiais com relação à resistência ao patógeno, além da inoculação com um isolado considerado agressivo, a inoculação demateriais também com uma mistura de isolados ou plantio deles em diferentes localidades com histórico de ocorrência da doença, de modo que se permita que o material seja exposto a uma população do patógeno. Assim, onível deresistência ea estabilidade da resistência do material de maracujazeiro serão conhecidos em vista do patógeno. Há trabalhos em outros patossistemas que contemplam essa questão da inoculação de mistura de isolados para se ter diversidade genética do patógeno e, assim, verificar-se a reação de resistência da planta ao patógeno. Por exemplo, MeHTAetal. (2006) inocularam doiscultivares de algodoeiro com uma mistura de nove isolados de Alternaria macrospora, visando a detectar a resistência dos materiais ao patógeno. GALBIERI et al. (2008), seguindo essa mesma linha, testaram 25 genótipos de algodoeiro quanto à resistência a Verticillium dahliae por meio de inoculação de uma mistura de quatro isolados do patógeno. Assim, os genótipos de algodoeiro selecionados como resistentes aos patógenos irão manter a resistência, mesmo quando plantados em diferentes localidades.

Conclui-se então que a variedade Afruvec de maracujazeiro amarelo é suscetível ao fungo $F$. solani. Dependendo do isolado, porém, o material pode apresentar suscetibilidade variável, tanto em relação à severidade da doença, quanto ao número de plantas mortas. Além disto, os isolados do fungo apresentam grande diversidade no que diz respeito à agressividade, evidenciando variabilidade genética na população. Essa última informação é importante para futuras seleções de materiais com relação à resistência ao patógeno.

\section{REFERÊNCIAS}

CAMARGO, L.E.A.; BERGAMIN FILHO, A. Controle genético. In: BERGAMIN FILHO, A.; KIMATI, H.; AMORIM, L. (Ed.). Manual de fitopatologia. v.1: Princípios e Conceitos. 3.ed. São Paulo: Agronômica Ceres, 1995. p.729-758.

CAMPBELL, C.D.; MADDEN, L.V. Introduction to plant disease epidemiology. New York: John Willey, 1990.

COLE, D.L.; HEDGES, T.R.; NDOWORA, T. A wilt of passion fruit (Passiflora edulis f. edulis Sims) caused by Fusarium solani and Phytophthora nicotianae var. parasitica. International Journal of Pest Management, v.38, n.4, p.362366, 1992.

DELANOË, O. Etude de la résistance de passiflores de Guyane française vis-à-vis de Fusarium pathogènes de la culture des fruits de la Passion (Passiflora edulis $\mathrm{f}$. flavicarpa). Fruits, v.46, n.5, p.593-600, 1991.

FISCHER, I.H.; KIMATI, H.; REZENDE, J.A.M. Doenças do maracujazeiro (Passiflora spp.). In: KIMATI, H.; AMORIM, L.; REZENDE, J.A.M.; BERGAMIN FILHO, A.; CAMARGO, L.E.A. (Ed.). Manual de fitopatologia. v.2: Doenças das plantas cultivadas. 4.ed. São Paulo: Agronômica Ceres, 2005a. p.467-474.

FISCHER, I.H.; LOURENÇO, S.A.; MARTINS, M.C.; KIMATI, H.; AMORIM, L. Seleção de plantas resistentes e de fungicidas para o controle da podridão do colo do maracujazeiro causada por Nectria hematococca. Fitopatologia Brasileira, v.30, n.3, p.250-258, 2005 b.

FISCHER, I.H.; REZENDE, J.A.M.; NALDI-FILHO, N.; SILVA, J.R. Ocorrência de Nectria haematococca em maracujazais no estado do Rio de Janeiro e resistência de Passiflora mucronata ao patógeno. Fitopatologia Brasileira, v.30, n.6, p.671, 2005c.

FNP CONSULTORIA \& AGROINFORMATIVOS. Maracujá. Agrianual: anuárco da agricultura brasileira. São Paulo: FNP, 2007. p.399-405.

GALBIERI, R.; CIA, E.; FUZATTO, M.G.; ITO, M.F.; LUDERS, R.R.; KONDO, J.I. Avaliação de genótipos de algodoeiro para resistência a Verticillium dahliae. Summa Phytopathologica, v.34, n.3, p.211-215, 2008.

LIN, Y.S.; CHANG, H.J. Collar rot of passion fruit possibly caused by Nectria haematococca in Taiwan. In: PARKER, C.A.; ROVIRA, A.D.; MOORE, K.J.; ONG, P.W.; KOLLMORGEN, J.F. (Ed.). Ecology and management of soilborne plant pathogens. St. Paul: APS Press, 1985. p.41-45. 
MEHTA, Y.R.; TEIXEIRA, E.; CUNHA, H.; ERIVALDO, J.; RUANO, O. Resposta diferencial das cultivares de algo-doeiro a Alternaria macrospora. Summa Phytopathologica, v.32, n.2, p.186-187, 2006.

RONCATTO, G.; OLIVEIRA, J.C.; RUGGIERO, C.; NOGUEIRA FILHO, G.C.; CENTURION, M.A.P.C.; FERREIRA, F.R. Comportamento de maracujazeiros (Passiflora spp.) quanto à morte prematura. Revista Brasileira de Fruticultura, v.26, n.3, p.552-554, 2004.
SSEKYEWA, C.; FINA OPIO, A.; SWINBURNE, T.R.; VAN DAMME, P.L.V.; ABUBAKAR, Z.M. Sustainable management of collar rot disease of passion fruits in Uganda. International Journal of Pest Management, v.45, n.3, p.173-177, 1999.

ZAR, J.S. Biostatistial Aanalysis. 4.ed. New Jersey: Prentice Hall, 1999.

Recebido em 6/4/09

Aceito em 20/7/10 